\title{
Multiplex PCR Assay for Identification of Six Different Staphylococcus spp. and Simultaneous Detection of Methicillin and Mupirocin Resistance
}

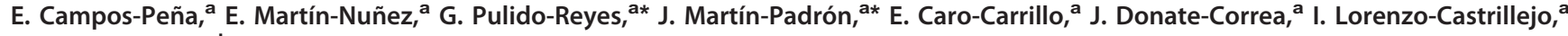 \\ J. Alcoba-Flórez, ${ }^{\text {a,b }}$ F. Machín, ${ }^{a}$ S. Méndez-Alvarez ${ }^{a, c}$

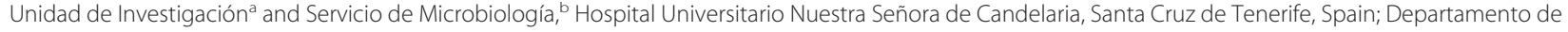 \\ Microbiología, Universidad de La Laguna, La Laguna, Spainc
}

\begin{abstract}
We describe a new, efficient, sensitive, and fast single-tube multiple-PCR protocol for the identification of the most clinically significant Staphylococcus spp. and the simultaneous detection of the methicillin and mupirocin resistance loci. The protocol identifies at the species level isolates belonging to S. aureus, S. epidermidis, S. haemolyticus, S. hominis, S. lugdunensis, and S. saprophyticus.
\end{abstract}

$\mathrm{H}$ umans are the main natural reservoir of the Gram-positive coagulase-positive bacterium Staphylococcus aureus (1). The continuous accumulation of resistance and virulence factors in this species has resulted in a worldwide health concern due to an associated increase in morbidity and mortality $(1,2,3)$. Hospital infections by this agent are particularly concerning, especially in those patients who are at risk for complications (i.e., immunocompromised patients, pregnant women, newborns and babies, cancer patients, individuals at dialysis programs, and transplant recipients, etc.) (4). Several methicillin-resistant S. aureus (MRSA) clones constitute a global alarm, often being epidemic or even a cause of pandemics $(5,6)$. However, within the genus Staphylococcus, S. aureus is not the only species that constitutes a worrisome pathogen. Thus, several coagulase-negative members of the genus are the etiological agents of diverse hospital-acquired severe infections. The most clinically significant examples are the species $S$. epidermidis, S. saprophyticus, S. lugdunensis, S. haemolyticus, and S. hominis (7-13). Their pathogenic features can become so hazardous that new, effective antibiotics and efficient, sensitive, and fast diagnostic methods constitute cornerstones in the fight against these adverse bacteria (12-15).

Introduction of novel drugs has always been followed by the prompt appearance of new staphylococcal resistances. Methicillin was introduced in 1959 to overcome the problems that arose from the increasing prevalence of penicillin-resistant $S$. aureus isolates (16). Two years later, MRSA strains were detected. Few antibiotics are still active against MRSA, with mupirocin being one of them. Mupirocin is normally used as a topical agent to prevent MRSA invasion $(17,18)$. Moreover, it is also a recommended antibiotic for use when invasive surgeries are performed (17). Unfortunately, 2 years after its introduction, high-level mupirocin resistance appeared and has worryingly increased since that time. Such resistance is commonly mediated by a conjugative plasmid-associated locus (ileS2) (19). Genetic transfer of ileS2 plasmids has given rise to mupirocin-resistant Staphylococcus clones belonging to several Staphylococcus species (20). The growing incidence of staphylococcus-resistant strains has created a need for the availability of Staphylococcus identification methods able to detect antibiotic resistance of multiple strains simultaneously, such as the new multiple-PCR (mPCR) protocol described in this study.
Bacterial isolates, identification, and susceptibility testing. A total of 67 clinical isolates were included in this study for the validation of the assay. Initially, 16 isolates were used to test all PCR primer pairs. All of these isolates were recovered from clinical samples from 67 patients at the Microbiology Service of the Hospital Universitario Nuestra Señora de Candelaria (HUNSC). Three S. aureus reference strains (ATCC 29213, ATCC 25923, and NCTC8325) were included in the study as well. Before the molecular analysis, all isolates were biochemically identified at the HUNSC Microbiology Service as follows. Clinical isolates were recovered by culturing clinical samples on Columbia agar plates with 5\% sheep blood and onto mannitol-salt agar (MSA) plates (bioMérieux, Marcy l'Etoile, France). Plates were incubated at 35 to $37^{\circ} \mathrm{C}$ for 24 to $48 \mathrm{~h}$ under aerobic conditions. Phenotypic identification of the isolates was done based on colony morphology, growth features on MSA, Gram staining, and catalase, coagulase, and DNase tests. Susceptibility testing was performed at the HUNSC Microbiology Service according to CLSI criteria $(21,22)$. Staphylococcus isolates were analyzed with the Vitek 2 system (GPS-511 card) (bioMérieux, Marcy l'Etoile, France). In addition, the susceptibility of the isolates to oxacillin and mupirocin was retested at the HUNSC Research Unit before molecular analysis was performed. Methicillin resistance was confirmed by disk diffusion testing with $1 \mu \mathrm{g}$ oxacillin, using Mueller-Hinton agar (Difco Laboratories, MI). Intermediate methicillin resistance was confirmed with oxacillin Etest strips (AB Biodisk). Mupirocin re-

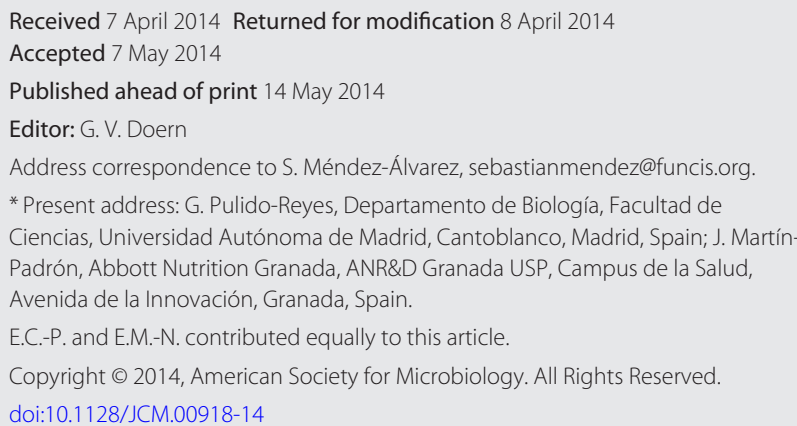


TABLE 1 Primers used in this study

\begin{tabular}{|c|c|c|c|c|c|}
\hline Target identification (locus) & Primer & Sequence $\left(5^{\prime}-3^{\prime}\right)$ & $T_{m}{ }^{a}$ & $\begin{array}{l}\text { Amplicon } \\
\text { size (bp) }\end{array}$ & Reference \\
\hline \multirow[t]{2}{*}{ S. lugdunensis ( $f b l$ ) } & $\mathrm{fblF}$ & AAA TCT CCA AGT TGA CCA AAC ATA C & 52.6 & 550 & Pereira et al., 2010 (11) \\
\hline & fblR & GAT TGC GCT GAA AGA ATT GC & 52.6 & & \\
\hline \multirow[t]{2}{*}{ Mupirocin resistance (ileS2) } & ileS2F (mup1) & TAT ATT ATG CGA TGG AAG GTT GG & 52.5 & 456 & Pérez-Roth et al., 2001 (20) \\
\hline & ileS2R (mup2) & AAT AAA ATC AGC TGG AAA GTG TTG & 52.5 & & \\
\hline \multirow[t]{2}{*}{ S. aureus (nuc) } & nucF & TCG CTT GCT ATG ATT GTG G & 52.9 & 359 & Hirotaki et al., 2011 (19) \\
\hline & nucR & GCC AAT GTT CTA CCA TAG C & 50.8 & & \\
\hline \multirow[t]{2}{*}{ Methicillin resistance ( $m e c A)$} & mecAl & GTA GAA ATG ACT GAA CGT CCG ATA A & 54.6 & 310 & Pérez-Roth et al., 2013 (18) \\
\hline & mecA2 & CCA ATT CCA CAT TGT TTC GGT CTA A & 55.7 & & \\
\hline S. epidermidis (sep) & sepR & CTG TAG AGT GAC AGT TTG GT & 51.7 & & \\
\hline \multirow[t]{2}{*}{ S. hominis (hom) } & homF & TAC AGG GCC ATT TAA AGA CG & 52.5 & 177 & Hirotaki et al., 2011 (19) \\
\hline & homR & GTT TCT GGT GTA TCA ACA CC & 51.1 & & \\
\hline
\end{tabular}

${ }^{a}$ Optimal annealing temperature.

sistance was screened by the disk diffusion method (Oxoid, Basingstoke, England): 5 - $\mu$ g mupirocin disks were used to detect lowlevel resistance, and 200- $\mu$ g disks were used to detect high-level resistance. Finally, confirmation of high-level resistance was performed with Etest strips (AB Biodisk, bioMérieux, Marcy l'Etoile, France), which yielded the exact MIC for every highly mupirocinresistant isolate (MIC, $\geq 1,024 \mu \mathrm{g} / \mathrm{ml}$ ).

Molecular biology analyses. The first step in the design of the mPCR was the selection of a variety of specific genes to identify at the species level clinical isolates from the six different staphylococcal species mentioned above and to detect high-level resistance to methicillin and/or mupirocin. The partially amplified loci are shown in Table 1. The primers selected for these amplifications had been previously described and were obtained from a commercial source (Integrated DNA Technologies, CA). For development of the mPCR, a DNA suspension from each isolate was rapidly prepared as previously described (19). Each primer pair was individually tested in a single PCR to ensure that the expected band was amplified (Fig. 1). Each of these single reactions was performed twice using DNA suspensions from two different isolates for each species. Moreover, some of the single PCRs have been used by us with collections of more than $200 \mathrm{~S}$. aureus isolates, more than 100 S. lugdunensis isolates, and more than 50 S. saprophyticus isolates (unpublished data). The reproducible success we achieved using these primers made us choose them for developing the MPCR described herein. Furthermore, we expected that different pairs would yield fragments with different sizes (Fig. 1 and Table 1), which would facilitate their identification after the mPCR. Thus, each band was purified (Qiagen purification kit; Qiagen, CA) and the sequence determined in order to confirm the identities by comparison to NCBI data bank sequences. Sequencing of the amplicons was performed on an ABI-PRISM 310 genetic analyzer (Applied Biosystems Japan Co. Ltd., Tokyo, Japan) with
BigDye terminator fluorescence chemistry (Applied Biosystems, Warrington, United Kingdom). In the case of the S. hominis isolate, the low prevalence of $m e c A$-positive $S$. hominis clinical infections in our hospital suggested the convenience of molecular identification by sequencing its $16 \mathrm{~S}$ rRNA genes. The $S$. hominis isolate 16S rRNA gene sequence had $99.9 \%$ identity with the S. hominis ATCC 27844 16S rRNA gene sequence (GenBank accession no. L37601.1). After band identity confirmation, the mPCR assay was optimized (Fig. 2), and the working protocol we used is described as follows. In a $25-\mu l$ reaction volume, $2.5 \mu \mathrm{l}$ of a DNA suspension was used as the DNA template, and it was added to a $22.5-\mu \mathrm{l}$ PCR mixture consisting of $1 \times$ reaction buffer, $0.2 \mathrm{mM}$ each of the four deoxynucleoside triphosphates (dNTPs), $2.4 \mathrm{mM} \mathrm{MgCl}_{2}, 1 \mu \mathrm{M}$ nucA primer pair, $0.5 \mu \mathrm{M} m v a A$ primer pair, $0.5 \mu \mathrm{M}$ sep primer pair, $0.5 \mu \mathrm{M} f b l$ primer pair, $0.5 \mu \mathrm{M}$ sap primer pair, $0.5 \mu \mathrm{M}$ mecA primer pair, $0.5 \mu \mathrm{M}$ ileS2 primer pair, $0.5 \mu \mathrm{M}$ hom primer pair, and $0.1 \mathrm{U} / \mu \mathrm{l}$ of Taq DNA polymerase (Biotherm DNA polymerase; Gene Craft, Germany). All mPCR assays were carried out with a negative control containing all reagents except the DNA template. DNA amplification was carried out in a GeneAmp PCR system 9700 thermocycler (PE Applied Biosystems, CA) with thermal cycling conditions consisting of an initial denaturization step at $94^{\circ} \mathrm{C}$ for $5 \mathrm{~min}$, followed by 45 amplification cycles of (i) 10 cycles of denaturization at $94^{\circ} \mathrm{C}$ for $30 \mathrm{~s}$, annealing at $64^{\circ} \mathrm{C}$ for 45 $\mathrm{s}$, and extension at $72^{\circ} \mathrm{C}$ for $45 \mathrm{~s}$; (ii) 10 cycles of denaturization at $94^{\circ} \mathrm{C}$ for $30 \mathrm{~s}$, annealing at $55^{\circ} \mathrm{C}$ for $45 \mathrm{~s}$, and extension at $72^{\circ} \mathrm{C}$ for $1 \mathrm{~min}$; and (iii) 25 cycles of denaturization at $94^{\circ} \mathrm{C}$ for $45 \mathrm{~s}$, annealing at $52^{\circ} \mathrm{C}$ for $45 \mathrm{~s}$, and extension at $72^{\circ} \mathrm{C}$ for $60 \mathrm{~s}$, ending with a final extension step at $72^{\circ} \mathrm{C}$ for $10 \mathrm{~min}$. After the mPCR, $4 \mu \mathrm{l}$ from the reaction tube was subjected to agarose gel electrophoresis ( $2 \%$ agarose, $1 \times$ Tris-borate-EDTA, $8.5 \mathrm{~V} / \mathrm{cm}, 75 \mathrm{~min})$, using a 100-bp molecular size standard ladder (Roche, Basel, Switzerland) to estimate the sizes of the amplification products. The gel 


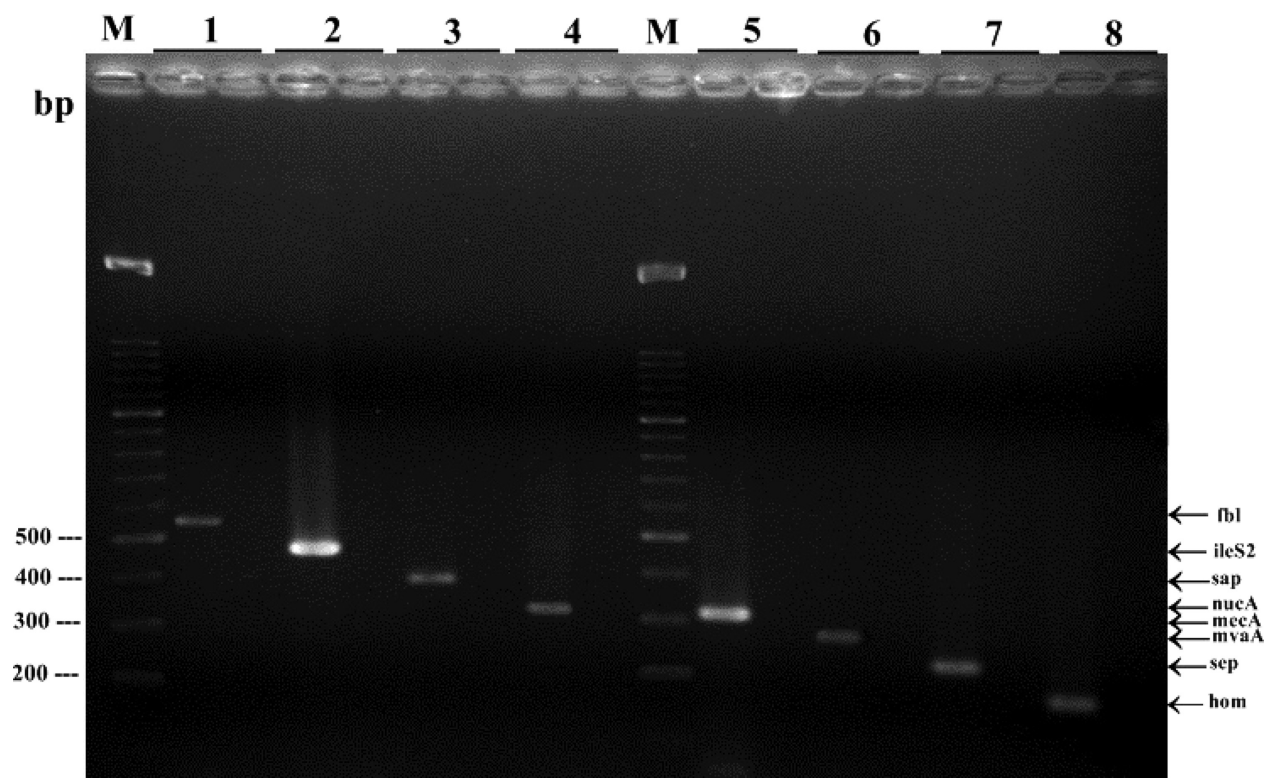

FIG 1 Agarose gel electrophoresis patterns showing single-PCR amplification products for S. lugdunensis gene $f b l$ (lane 1), mupirocin resistance gene ileS2 (lane 2), S. saprophyticus gene sap (lane 3), S. aureus gene nucA (lane 4), methicillin resistance gene mecA (lane 5), S. haemolyticus gene mvaA (lane 6), S. epidermidis gene sep (lane 7), and S. hominis gene hom (lane 8). Each pair of primers was amplified together with a negative control without DNA.

was stained with ethidium bromide, and the amplicons were visualized using a UV light in a GelDoc System (Bio-Rad, CA).

Method comparison studies. The concordance, efficiency, reproducibility, sensitivity, typeability, and discrimination power of the MPCR were estimated by use of bivariate ratios and the Simp-

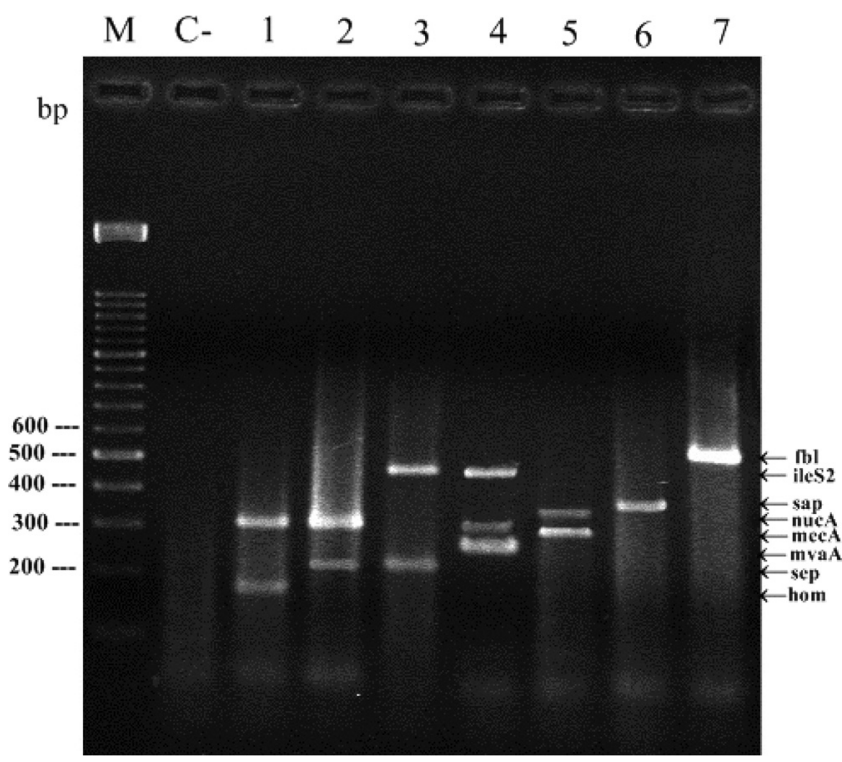

FIG 2 Agarose gel electrophoresis patterns showing mPCR amplification products from different staphyloccocal isolates. Lanes: C-, negative control without DNA; 1, methicillin-resistant $S$. hominis isolate (hom and mecA bands); 2, methicillin-resistant S. epidermidis isolate (sep and mecA bands); 3 , mupirocin-resistant S. epidermidis isolate (sep and ileS2 bands); 4: methicillinand mupirocin-resistant $S$. haemolyticus isolate (mvaA, mecA, and ileS2 bands); 5: methicillin-resistant $S$. aureus isolate (nucA and mecA bands); 6: methicillin- and mupirocin-susceptible S. saprophyticus isolate (sap band); 7: methicillin- and mupirocin-susceptible $S$. lugdunensis ( $f b l$ band). son diversity index. Moreover, combined comparative analyses of gel images and phenotypic data were performed by using the Infoquest fingerprinting system, version 4.5 (Bio-Rad, CA).

Results. After the mPCR was performed for all 67 isolates, the $n u c A$ fragment amplified only in S. aureus strains and never in other staphylococcal isolates. Similarly, $f b l, m v a A$, sap, sep, and hom fragments yielded fragments only in S. lugdunensis, S. haemolyticus, S. saprophyticus, S. epidermidis, and S. hominis strains, respectively. As for the mecA fragment, it was detected in all strains that exhibited high methicillin resistance but not in the methicillin-sensitive ones. Similarly, amplification of the ileS2 target always occurred for highly mupirocin-resistant strains, never for isolates with low or intermediate resistance, and never for the susceptible ones. The mPCR results for the isolates tested in this study are shown in Table 2.

After the 67 Staphylococcus isolates were analyzed with phenotypic, biochemical, and microbiological tools, single PCRs, and the newly described $\mathrm{MPCR}$, the concordance of identification by classical methods with mPCR identification had a value of 1

TABLE 2 Staphylococcal clinical isolates, identification at the species level, susceptibilities to methicillin and mupirocin, and mPCR results

\begin{tabular}{llllll}
\hline \multirow{5}{*}{ Species } & \multicolumn{4}{l}{ No. of isolates } \\
\cline { 2 - 6 } & Total & Mup $^{\mathrm{r}}$ & Met $^{\mathrm{r}}$ & Mup $^{\mathrm{r}} \mathrm{Met}^{\mathrm{r}}$ & Mup $^{\mathrm{s}} \mathrm{Met}^{\mathrm{s}}$ \\
\hline S. aureus & 31 & 2 & 19 & 5 & 5 \\
S. epidermidis & 14 & 3 & 2 & 0 & 9 \\
S. hominis & 1 & 0 & 1 & 0 & 0 \\
S. saprophyticus & 12 & 1 & 1 & 0 & 10 \\
S. haemolyticus & 3 & 0 & 1 & 2 & 0 \\
S. lugdunensis & 6 & 0 & 0 & 0 & 6 \\
Total & 67 & 6 & 24 & 7 & 30 \\
\hline
\end{tabular}

${ }^{a}$ Mup, mupirocin; Met, methicillin; r, resistant; s, susceptible. 
(100\%), a sensitivity value of $1(100 \%)$, and a specificity value of 1 (100\%), a typeability value of 1 (100\%), a reproducibility value of $\geq 0.95$, and a discriminatory power of 0.9225 (http://insilico.ehu .es/mini_tools/discriminatory_power/index.php).

Concluding remarks. The clinical infections described here constitute health concerns, and therefore prompt identification of the staphylococcal infectious agents and the precise detection of their antibiotic resistances are crucial for successful management (7-9, 18-20). With these aims, we have developed a new singletube multiple PCR assay that is very fast, extremely efficient, and sensitive. A limitation of this multiplex assay is that it can identify only $S$. aureus and the five above-mentioned coagulase-negative staphylococcal species. However, according to the literature (23), we have included the most clinically significant Staphylococcus spp., which are also the most frequently isolated in our hospital. Other species, such as Staphylococcus schleiferi and Staphylococcus capitis, have been rarely associated with endophthalmitis after surgery and neonatal sepsis, respectively, in some studies (17), but they have not caused complications in our hospital. Another possible limitation of the present study is the small number of methicillin- and/or mupirocin-resistant isolates we tested. But, as we have mentioned above, the larger number of isolates analyzed by single PCR reinforces the dependability of this multiplex PCR. In comparison with good previously described methods, such as the quadriplex PCR described by Zhang et al. (13), this new protocol has the advantage of obtaining species-specific amplicons, which permits species identification without the need for sequencing PCR fragments after the PCR. This protocol, from the preparation of cellular suspension to electrophoresis analysis of the PCR products on agarose gel, was performed in 5 to $6 \mathrm{~h}$. The knowledge provided by the results obtained should dictate the appropriate antibiotic therapy in concert with preemptive measurements.

\section{ACKNOWLEDGMENTS}

This work was partially supported by grants from the Instituto de Salud Carlos III (Spanish Health Ministry), namely, grant PS10/00125 to S.M.-A. and grant PS12/00280 to F.M. We also acknowledge cofunding by the European Region Development Funds (ERDF).

\section{REFERENCES}

1. Chua KY, Howden BP, Jiang JH, Stinear T, Peleg AY. 2013. Population genetics and the evolution of virulence in Staphylococcus aureus. Infect. Genet. Evol. 21:554-562. http://dx.doi.org/10.1016/j.meegid.2013 .04 .026 .

2. Holden MT, Feil EJ, Lindsay JA, Peacock SJ, Day NP, Enright MC, Foster TJ, Moore CE, Hurst L, Atkin R, Barron A, Bason N, Bentley SD, Chillingworth C, Chillingworth T, Churcher C, Clark L, Corton C, Cronin A, Doggett J, Dowd L, Feltwell T, Hance Z, Harris B, Hauser H, Holroyd S, Jagels K, James KD, Lennard N, Line A, Mayes R, Moule S, Mungall K, Ormond D, Quail MA, Rabbinowitsch E, Rutherford K, Sanders M, Sharp S, Simmonds M, Stevens K, Whitehead S, Barrell BG, Spratt BG, Parkhill J. 2004. Complete genomes of two clinical S. aureus strains: evidence for the rapid evolution of virulence and drug resistance. Proc. Natl. Acad. Sci. U. S. A. 101:9786-9791. http://dx.doi.org/10.1073 /pnas.0402521101.

3. van Hal SJ, Jensen SO, Vaska VL, Espedido BA, Paterson DL, Gosbell IB. 2012. Predictors of mortality in Staphylococcus aureus bacteremia. Clin. Microbiol. Rev. 25:362-386. http://dx.doi.org/10.1128/CMR.05022-11.

4. Sharma P, Kaur P, Aggarwal A. 2013. S. aureus - the predominant pathogen in the neonatal ICU of a tertiary care hospital in Amritsar, India. J. Clin. Diagn. Res. 7:66-69. http://dx.doi.org/10.7860/JCDR/2012/4913 .2672.

5. Coates T, Bax R, Coates A. 2009. Nasal decolonization of Staphylococcus aureus with mupirocin: strengths, weaknesses and future prospects. J. Antimicrob. Chemother. 64:9-15. http://dx.doi.org/10.1093/jac/dkp159.
6. Uhlemann AC, Otto M, Lowy FD, Deleo FR. 2014. Evolution of community- and healthcare-associated methicillin-resistant Staphylococcus aureus. Infect. Genet. Evol. 21:563-574. http://dx.doi.org/10.1016/j.meegid.2013 .04 .030 .

7. Rivero-Pérez B, Alcoba-Flórez J, Méndez-Álvarez S. 2012. Genetic diversity of community-associated methicillin-resistant Staphylococcus aureus isolated from Tenerife Island, Spain. Infect. Genet. Evol. 12:586-590. http://dx.doi.org/10.1016/j.meegid.2012.02.007.

8. Martineau F, Picard FJ, Ménard C, Roy PH, Ouellette M, Bergeron MG. 2000. Development of a rapid PCR assay specific for Staphylococcus saprophyticus and application to direct detection from urine samples. J. Clin. Microbiol. 38:3280-3284.

9. Baquero F, Coque TM, de la Cruz F. 2011. Ecology and evolution as targets: the need for novel eco-evo drugs and strategies to fight antibiotic resistance. Antimicrob. Agents Chemother. 55:3649-3660. http://dx.doi .org/10.1128/AAC.00013-11.

10. Otto M. 2009. Staphylococcus epidermidis - the 'accidental' pathogen. Nat. Rev. Microbiol. 7:555-567. http://dx.doi.org/10.1038/nrmicro2182.

11. Pereira EM, Oliveira FL, Schuenck RP, Zoletti GO, Dos Santos KR. 2010. Detection of Staphylococcus lugdunensis by a new species-specific PCR bassed on the $f b l$ gene. FEMS Immunol. Med. Microbiol. 52:295-298. http://dx.doi.org/10.1111/j.1574-695X.2009.00626.x.

12. Schuenck RP, Pereira EM, Iorio NLP, Dos Santos KRN. 2008. Multiplex PCR assay to identify methicillin-resistant Staphylococcus haemolyticus. FEMS Immunol. Med. Microbiol. 52:431-435. http://dx.doi.org/10.1111 /j.1574-695X.2008.00387.x.

13. Zhang L, Thomas JC, Miragaia M, Bouchami O, Chaves F, d'Azevedo PA, Aanensen DM, de Lencastre H, Gray BM, Robinson DA. 2013. Multilocus sequence typing and further genetic characterization of the enigmatic pathogen, Staphylococcus hominis. PLoS One 8:e66496. http: //dx.doi.org/10.1371/journal.pone.0066496.

14. Casero C, Estévez-Braun A, Ravelo AG, Demo M, Méndez-Álvarez S, Machín F. 2013. Achyrofuran is an antibacterial agent capable of killing methicillin-resistant Van-intermediate Staphylococcus aureus in the nanomolar range. Phytomedicine 20:133. http://dx.doi.org/10.1016/j.phymed .2012.11.003.

15. Peña R, Jiménez-Alonso S, Feresin G, Tapia A, Méndez-Alvarez $S$, Machín F, Ravelo 'A, Estévez-Braun GA. 2013. Multicomponent synthesis of antibacterial dihydropyridin and dihydropyran embelin derivatives. J. Org. Chem. 78:7977-7985. http://dx.doi.org/10.1021/jo401189x.

16. Jevons MP, Coe AW, Parker MT. 1963. Methicillin resistance in staphylococci. Lancet i:904-907.

17. Delaney HM, Wang E, Melish M. 2013. Comprehensive strategy including prophylactic mupirocin to reduce Staphylococcus aureus colonization and infection in high-risk neonates. J. Perinatol. 33:313-318. http://dx.doi .org/10.1038/jp.2012.102.

18. Pérez-Roth E, Potel-Alvarellos C, Espartero X, Constela-Caramés L, Méndez-Álvarez S, Alvarez-Fernández M. 2013. Molecular epidemiology of plasmid-mediated high-level mupirocin resistance in methicillinresistant Staphylococcus aureus in four Spanish health care settings. Int. J. Med. Microbiol. 303:201-204. http://dx.doi.org/10.1016/j.ijmm.2013.03 .003 .

19. Hirotaki S, Sasaki T, Kuwahara-Arai K, Hiramatsu K. 2011. Rapid and accurate identification of human-associated staphylococci by use of multiplex PCR. J. Clin. Microbiol. 49:3627-3631. http://dx.doi.org/10.1128 /JCM.00488-11.

20. Pérez-Roth E, Claverie-Martín F, Villar J, Méndez-Alvarez S. 2001. Multiplex PCR for simultaneous identification of Staphylococcus aureus and detection of methicillin and mupirocin resistance. J. Clin. Microbiol. 39:4037-4041. http://dx.doi.org/10.1128/JCM.39.11.4037-4041.2001.

21. Clinical and Laboratory Standards Institute. 2012. Performance standards for antimicrobial disk susceptibility tests; approved standard-11th ed. CLSI document M02-A11. Clinical and Laboratory Standards Institute, Wayne, PA. http: //antimicrobianos.com.ar/ATB/wp-content/uploads/2012/11/01-CLSI-M02-A1 1-2012.pdf.

22. Clinical and Laboratory Standards Institute. 2014. Performance standards for antimicrobial susceptibility testing; 24th informational supplement. CLSI document M100-S24. Clinical and Laboratory Standards Institute, Wayne, PA. http://shopping.netsuite.com/c.1253739/site/Sample _pdf/M100S24_sample.pdf.

23. Murray P, Baron EJ, Jorgensen JH, Landry ML, Pfaller MA (ed). 2007. Manual of clinical microbiology, 9th ed. ASM Press, Washington, DC. 